\title{
Detection of lead nanoparticles in game meat by single particle ICP-MS following use of lead-containing bullets
}

\author{
Kollander, Barbro; Widemo, Fredrik; Ågren, Erik; Larsen, Erik Huusfeldt; Löschner, Katrin
}

Published in:

Analytical and Bioanalytical Chemistry

Link to article, DOI:

$10.1007 / \mathrm{s} 00216-016-0132-6$

Publication date:

2017

Document Version

Peer reviewed version

Link back to DTU Orbit

Citation (APA):

Kollander, B., Widemo, F., Ågren, E., Larsen, E. H., \& Löschner, K. (2017). Detection of lead nanoparticles in game meat by single particle ICP-MS following use of lead-containing bullets. Analytical and Bioanalytical Chemistry, 409(7), 1877-1885. https://doi.org/10.1007/s00216-016-0132-6

\section{General rights}

Copyright and moral rights for the publications made accessible in the public portal are retained by the authors and/or other copyright owners and it is a condition of accessing publications that users recognise and abide by the legal requirements associated with these rights.

- Users may download and print one copy of any publication from the public portal for the purpose of private study or research.

- You may not further distribute the material or use it for any profit-making activity or commercial gain

- You may freely distribute the URL identifying the publication in the public portal 
The final publication is available at Springer via http://dx.doi.org/10.1007/s00216016-0132-6

\section{Detection of lead nanoparticles in game meat by single particle ICP-MS following use of lead-containing bullets}

Barbro Kollander ${ }^{1}$, Fredrik Widemo ${ }^{2,3}$, Erik Ågren ${ }^{4}$, Erik H. Larsen ${ }^{5}$, Katrin Loeschner ${ }^{5}$

${ }^{1}$ National Food Agency, P.O. Box 622, SE-751 26 Uppsala, Sweden

${ }^{2}$ Department of wildlife, fish and environmental studies, Swedish University of Agriculture Science, SE-901 83 Umeå, Sweden

${ }^{3}$ Swedish Association for Hunting and Wildlife Management, Öster Malma, SE-611 91 Nyköping, Sweden

${ }^{4}$ National Veterinary Institute, Dept. of Pathology and Wildlife Diseases, National Veterinary Institute, SE75189 Uppsala, Sweden

${ }^{5}$ Division for Food Technology, National Food Institute, Technical University of Denmark, Mørkhøj Bygade 19, DK-2860 Søborg, Denmark

Corresponding author:

Katrin Loeschner

Phone: +4535887029

Fax: +4535887448

Email:kals@food.dtu.dk 


\section{Abstract}

This study investigated whether game meat may contain nanoparticles of lead from ammunition. Lead nanoparticles in the range 40 to $750 \mathrm{~nm}$ were detected by ICP-MS in single particle mode in game shot with lead-containing bullets. The median diameter of the detected nanoparticles was around $60 \mathrm{~nm}$. The particle mass concentration ranged from 290 to $340 \mathrm{ng} / \mathrm{g}$ meat and the particle number concentrations from 27 to 50 million particles/g meat. The size limit of detection strongly depended on the level of dissolved lead and was in the range of 40 to $80 \mathrm{~nm}$. In game meat sampled more than $10 \mathrm{~cm}$ away from the wound channel no lead particles with a diameter larger than $40 \mathrm{~nm}$ were detected. In addition to dissolved lead in meat that originated from particulates, the presence of lead nano particles in game meat represents a hitherto unattended source of lead with a largely unknown toxicological impact to humans.
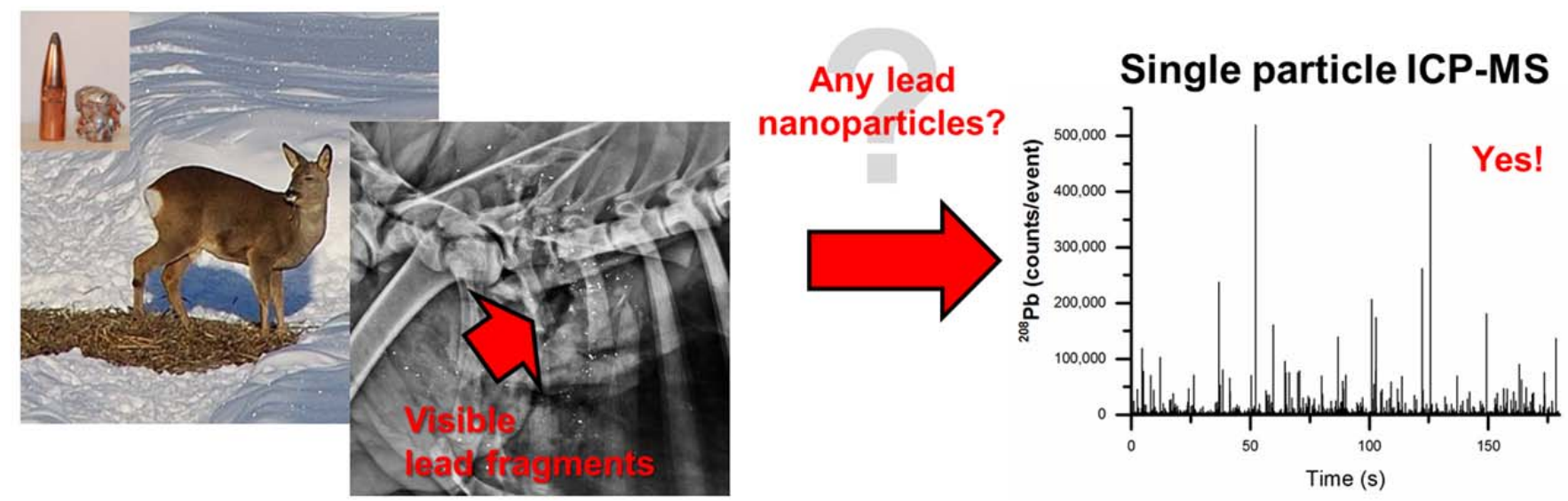

\section{Keywords}

lead nanoparticles, single particle ICP-MS, lead ammunition, game, enzymatic digestion

\section{Introduction}

Lead $(\mathrm{Pb})$ is a toxic metal that accumulates in the body and seriously affects the developing central nervous system in young children, but may also induce e.g. negative cardiovascular effects and nephrotoxicity in adults (EFSA 2010) [1]. The European Food Safety Authority (EFSA) [2] and the Joint FAO/WHO Expert Committee for Food Additives (JECFA) [3] no longer support the previously used provisional tolerable weekly intake (PTWI) of $25 \mu \mathrm{g} \mathrm{Pb} / \mathrm{kg}$ body weight, as it no longer can be considered as health protective. Today, the consensus is that there is no safe level of $\mathrm{Pb}$, especially for infants, children and the fetuses of pregnant women [3].

Food is the major source of human exposure to $\mathrm{Pb}$, particularly via foodstuffs based on cereals or tap water (EFSA 2010) [1]. While game meat constitutes a very small part of the diet for average citizens, game meat can be a major food commodity and therefore source of $\mathrm{Pb}$ exposure for high consumers. This is because game meat may contain very high levels of $\mathrm{Pb}$ in the form of fragments from the $\mathrm{Pb}$ core bullet used to cull 
the game $[4,5]$. As a result, consumption of game meat has been associated with increased $\mathrm{Pb}$ levels in blood [6-8], even though the reported bio-accessibility of the ingested fragments is low [9]. While lead free alternatives exist, lead core bullets are used by most hunters in most countries, and bans on lead in bullets are rare exceptions [10].

During the penetration of the game body, expanding $\mathrm{Pb}$ core bullets typically release hundreds or thousands of fragments of varying size that can be visualized using X-rys [10, 11]. In the process, a significant part of the kinetic energy of the bullet is converted to plastic deformation and heating, causing some of the exposed $\mathrm{Pb}$ to melt on or even vaporize from the surface of the expanding bullet and its fragments [12]. Potentially, upon cooling, this may cause $\mathrm{Pb}$ particles to be formed through re-solidification, some of which are too small to be detected by X-Ray techniques.

A hitherto neglected route of $\mathrm{Pb}$ exposure from consumption of game meat is as metallic lead nanoparticles (PbNPs). To our knowledge nothing is known about the occurrence or toxicology of this form of $\mathrm{Pb}$. Three principles of possible adverse effects, that are unique to nanoparticles, have been identified [13]. The "transport principle" suggests that materials with a certain possible toxic effect (like $\mathrm{Pb}$ ) may be particularly potent when they are in the nanoparticle-form. Uptake of ions and molecules by cells is usually biochemically regulated. In contrast, NPs that do not dissolve, but remain stable for a long time or accumulate in cells, may become "active" in another way. The "surface principle" suggests that the small size of NPs may cause enhanced chemical reactivity by the large number of surface atoms and by surface effects, such as crystal lattice defects. The associated toxicity, however, also strongly depends on the characteristics of the nanomaterial itself including material properties, material composition, potential impurities and surface modifications etc., and is named the "material principle".

In general, there is no consensus on the gastrointestinal uptake of NPs. The assessment of gastrointestinal absorption and biological effects of ingested NPs presents many problems because of its complexity [14] and only few in vivo absorption studies have been identified as robust and valid for nanoparticle studies [15]. Future work is therefore needed to demonstrate if PbNPs may represent an additional route of direct or indirect uptake of $\mathrm{Pb}$ in the gastro-intestinal system.

Inductively coupled plasma-mass spectrometry (ICP-MS) used in single particle mode (spICP-MS) has been shown to be a powerful instrumental technique for determination of size distribution of NPs [16]. spICP-MS uses the well-established technique of ICP-MS on a "particle by particle" basis [16]. This requires sufficiently high dilution of the NP suspension to the nanogram per liter concentration range and mass spectrometer dwell times set in the micro- to millisecond range. The theory of ICP-MS used in single particle mode for characterization of colloids in water has been introduced by Degueldre et al. [17]. The technique can distinguish between ionic and nanoparticle forms of an element and provide (number-based) particle size distribution [17-19]. For spICP-MS the sample needs to be in liquid suspension. Therefore, 
when applied to detection of PbNPs in meat, suitable sample preparation is necessary. Simple dilution and centrifugation has been shown to be unsuccessful for lean chicken meat containing silver NPs, due to the strong affinity of these NPs to the meat matrix [20]. Consequently, decomposition of the matrix by strong acids, bases or enzymes is necessary to liberate the NPs into liquid suspension. The decomposition of the matrix should be performed without altering any of the characteristics of the NPs, which excludes use of certain strong acids or bases for the less noble metallic NPs, such as $\mathrm{Pb}$. A previously developed enzymatic digestion procedure for silver NPs in chicken meat [20] has proven to be applicable as sample preparation method prior to nanoparticle analysis for other biological samples, including rat spleen [21] and human hip fluid [22].

Here, we investigate the prevalence and size distribution of PbNPs from ammunition in game meat, using spICP-MS and a modified version of the earlier described enzymatic digestion method [20]. To the best of our knowledge, this is the first study of the contribution to $\mathrm{Pb}$ exposure by PbNPs in a food commodity. The results are highly relevant for risk assessment and risk management in generating advice for consumption and handling of game meat.

\section{Materials and methods}

\subsection{Materials}

\subsubsection{Game meat samples}

In 2013-2014, the Swedish National Food Agency (NFA), the Swedish Association for Hunting and Wildlife Management (SAHWM) and the Swedish National Veterinary Institute investigated $\mathrm{Pb}$ levels from ammunition in game meat and the best practice for handling game carcasses [9, 23, 24]. Samples were taken from cuts at increasing distances from the wound channel from the bullet, in order to be able to determine how much meat has to be removed for reducing $\mathrm{Pb}$ levels to acceptable levels. The results led to advice that all meat visibly affected and an additional $10 \mathrm{~cm}$ of meat that appeared unaffected in a radius around the wound channel should be discarded. Consequently, meat taken $10 \mathrm{~cm}$ or further away from the wound channel should be regarded as "safe" to consume in terms of $\mathrm{Pb}$ concentration level.

In the present investigation, some of the same samples were also investigated for the occurrence of PbNPs. The samples that were subjected to NP analysis were collected from one roe deer shot using Norma Oryx ammunition with a bullet weight of 11.7 grams and fired from a caliber 308 Winchester rifle. This bullet is a bonded $\mathrm{Pb}$ core bullet, which expands and partly fragments upon impact with the targeted animal. Also, samples from one wild boar were collected from the Swedish Association for Hunting and Wildlife Management (SAHWM) game processing plant. The type of ammunition used for culling the wild boar was not documented. X-Rays of the carcasses however, showed the presence of bullet fragments and $\mathrm{Pb}$ analyses 
of the meat demonstrated high levels of $\mathrm{Pb}$ in the meat around the wound channel. Thus, expanding $\mathrm{Pb}$ core bullets were used for taking down the roe deer and wild boar.

From the roe deer carcass, subsamples of finely minced meat were sampled around the wound channel (high probability of PbNPs, not intended for consumption) and sampled from the steak from the hind quarter of the animal (low probability of PbNPs; no lead detected in previous study and intended for consumption). From the wild boar, a subsample was taken directly from the bloodshot meat surrounding the wound channel. After removing all visibly affected meat around the wound channel, another sample was taken 10$15 \mathrm{~cm}$ away from the already cleaned wound channel. The total $\mathrm{Pb}$ mass concentrations reported in the previous study for these samples were around $300 \mu \mathrm{g} / \mathrm{g}$ in both wound channel samples (roe deer and wild boar). It should be noted that some wild boar samples in the original study contained lead at several thousand $\mu \mathrm{g} / \mathrm{g}$, so the samples investigated for PbNPs were not extreme [9]. The $\mathrm{Pb}$ mass concentrations in the "low probability for PbNPs-samples" were $<0.004 \mu \mathrm{g} / \mathrm{g}$ for the roe deer steak and $0.05 \mu \mathrm{g} / \mathrm{g}$ for the wild boar taken sample taken 10-15 cm away from the wound channel. The meat intended for consumption will be called "control samples" in the following text.

\subsubsection{Chemicals}

Ultrapure water $(18.2 \mathrm{~m} \Omega / \mathrm{cm})$ was obtained from a Millipore Element apparatus (Millipore, Milford, MA, USA) and used throughout the work. ReagentPlus sodium dodecyl sulphate (SDS) with $\geq 98.5 \%$ purity and sodium azide with $\geq 98 \%$ purity were purchased from Sigma-Aldrich (St. Louis, MO, USA). For the enzymatic digestion the commercial protease Proteinase K from Engyodontium album was used (SigmaAldrich St. Louis, MO, USA). Proteinase K is a serine protease with a molecular mass $28930 \mathrm{Da}$, a broad $\mathrm{pH}$ range of 7.5-12 and a temperature optimum of $37^{\circ} \mathrm{C}$ regarding its enzyme activity. Nitric acid (67-69\%) of PlasmaPURE quality and single element PlasmaCAL standard of $\mathrm{Pb}$ at $1000 \mu \mathrm{g} / \mathrm{mL}$ were obtained from SCP Science (Baie D'Urfé, QC, Canada). For determination of the transport efficiency for spICP-MS analyses a gold nanoparticle (AuNP) Reference Material suspension with $60 \mathrm{~nm}$ in nominal diameter (RM8013) was obtained from the National Institute for Science and Technology, NIST (Gaithersburg, MD, USA).

\subsection{Instrumentation}

The homogenized subsamples from a previous study [9] were X-Rayed using the Rotopractix 90/20 together with a Regius Model 110 S direct digitizer. An UltraTurrax homogenizer (IKA Werke GmbH \& Co. KG, Staufen, Germany) was used for preparation of slurries of the meat samples. During enzymatic digestion a water bath with a Heto HMT 200 RS thermostat and a Telesystem HP15 magnetic stirrer (Holm \& Halby, Allerød, Denmark) was used. 
An iCAP Q ICP-MS instrument (Thermo Fisher Scientific GmbH, Bremen, Germany) was used for all spICP-MS experiments. Instrument tuning was performed prior to analysis by using a tuning solution according to the manufacturer's recommendation. Instrument settings are given in Table 1.

Table 1: spICP-MS settings

\begin{tabular}{|l|l|}
\hline Parameter (unit) & Value \\
\hline RF power $(\mathrm{W})$ & 1,550 \\
\hline Plasma gas flow rate $(\mathrm{L} / \mathrm{min})$ & 14 \\
\hline Nebulizer gas flow rate $(\mathrm{mL} / \mathrm{min})$ & 1.10 \\
\hline Auxiliary gas flow rate $(\mathrm{mL} / \mathrm{min})$ & 0.65 \\
\hline Cell gas (flow rate) $(\mathrm{mL} / \mathrm{min})$ & $\mathrm{n} / \mathrm{a}$ \\
\hline Sample uptake flow rate $(\mathrm{mL} / \mathrm{min})$ & $\sim 0.4^{\mathrm{a}}$ \\
\hline Monitored isotopes $(\mathrm{m} / \mathrm{z})$ & ${ }^{197} \mathrm{Au}^{\mathrm{b}},{ }^{208} \mathrm{~Pb}$ \\
\hline Dwell time $(\mathrm{ms})$ & 5 \\
\hline Analysis time $(\mathrm{s})$ & $60-180$ \\
\hline Nebulizer type & Low-flow concentric nebulizer \\
\hline Spray chamber type & Cyclonic, Peltier-cooled \\
\hline \\
\\
a Determined on a daily basis (corresponding peristaltic pump speed was 40 rounds $/ \mathrm{min})$
\end{tabular}

\subsection{Methods}

\subsubsection{Sample preparation for spICP-MS}

The sampled, complete tissue mass was mixed with the same mass of water and homogenized using the Ultra Turrax homogenizer. The samples for further analysis were taken from the resulting viscous slurry. A previously developed enzymatic digestion procedure was modified and applied [20]. In this work, enzymatic digestion for one or 16 hours was tested separately to illustrate any possible dissolution of PbNPs during enzymatic digestion. Briefly, the enzyme solution was prepared by dissolving Proteinase $\mathrm{K}$ to a final concentration of $3 \mathrm{mg} / \mathrm{mL}$ in $50 \mathrm{mM}$ ammonium bicarbonate buffer (pH 7.4-7.7) containing $5 \mathrm{mg} / \mathrm{mL}$ SDS and $0.2 \mathrm{mg} / \mathrm{mL}$ sodium azide (antimicrobial agent). A portion of $0.2 \mathrm{~g}$ meat homogenate was weighed and $2 \mathrm{~mL}$ of the Proteinase $\mathrm{K}$ solution and $0.3 \mathrm{~mL}$ water added. The resulting ratio between enzyme and dry matter of meat (estimated as $30 \%$ of total wet mass) was approximately $1: 5 \mathrm{~m} / \mathrm{m}$. The mixture was incubated at $37^{\circ} \mathrm{C}$ in a water bath using continuous stirring for one or 16 hours. After treatment the samples were placed in ice water to stop the enzymatic activity. As a sample preparation blank, ultrapure water was treated using the same procedure.

\subsubsection{Particle analysis by spICP-MS}

Data processing was performed according to the methodology described by Pace [25] using a spread sheet routine. The peristaltic pump of the inlet system of the ICP-MS was set to 40 rounds per minute for all experiments, which corresponded to a sample flow rate of approximately $0.4 \mathrm{~mL} / \mathrm{min}$, which was accurately 
determined daily by weighing using pure water at room temperature as sample. A calibration curve was constructed following analysis of an acid blank solution and five $\mathrm{Pb}$ standards ranging from 0.2 to $5.0 \mu \mathrm{g} / \mathrm{L}$ diluted in $2 \%$ nitric acid prepared from a certified solution. $2 \%$ nitric acid was used as a diluent because no linear calibration curve could be obtained in ultrapure water, most likely due to adhesion effects. The ${ }^{208} \mathrm{~Pb}$ intensity for each solution was then averaged from the entire length of the analysis (60 s). The transport efficiency of the liquid samples through the sample introduction system was determined according to the "particle frequency" method [25] by measuring a NIST RM8013 AuNP suspension with an average particle diameter of $56.0 \mathrm{~nm}$ (based on measurements by transmission electron microscopy provided by NIST) and a gold mass concentration of $51.86 \pm 0.64 \mu \mathrm{g} / \mathrm{g}$ (information value provided by NIST), diluted $10^{6}$-times with ultrapure water. The transport efficiency was calculated as the percentage of all Au nanoparticles detected by spICP-MS versus the theoretical (calculated) particle number in the introduced sample volume, derived from the TEM-based size distribution published in the NIST Report of Investigation, the measured uptake rate and time of introduction of the sample suspension into the ICP-MS instrument.

Samples were diluted 66.7-times with ultrapure water prior to analysis. For each sample the ${ }^{208} \mathrm{~Pb}$ signal intensity was recorded for $180 \mathrm{~s}$ using a dwell time of $5 \mathrm{~ms}$, which corresponded to 36,000 recorded data points. The isotope ${ }^{208} \mathrm{~Pb}$ was selected because it is the most abundant isotope of $\mathrm{Pb}(52.40 \%)$. Following the analysis of each sample, ultrapure water was analyzed for $180 \mathrm{~s}$ to illustrate if carry-over from the previous measurement could be excluded. For all analyses, the recorded signal intensity data were plotted (in cps) versus number of "events", to create a signal distribution. The low, stable and relatively noise-free signal intensities were considered to be caused by instrument background and polyatomic interferences or, for slightly higher intensity values, also caused by dissolved $\mathrm{Pb}$ (ions and molecules) in the sample. An iterative algorithm was applied where particle events were distinguished as outliers from the polyatomic background and dissolved metal signal if the measured intensity was more than five times the standard deviation of the whole data set $[22,26]$. This criterion ensured that only NPs and no background or signal from Pb ions or molecules were included in the dataset, but also excluded low-intensity events corresponding to the smallest NPs. Particle size histograms were plotted using OriginPro 2016 (OriginLab Corporation, MA, USA).

\section{Results and discussion}

\subsection{X-ray of carcasses and samples}

The X-Ray images of the skinned wild boar shoulder showed a substantial amount of fragments close to the wound channel (Fig. 1a). The lower limit of size detection of $\mathrm{Pb}$ fragments in the digital X-Ray images was estimated at approximately $0.1 \mathrm{~mm}$. Chipped bones can, like metal fragments, be seen as a radiopaque object, but the metal density is so much greater that the material can be visually distinguished when examining the samples. Fig. $1 \mathrm{~b}$ presents the X-Ray image of the flattened wound channel subsample later used for spICP-MS analysis. Visible fragments $(>0.1 \mathrm{~mm})$ are present in the sample. In previous work [9] a positive relationship between the number of fragments and the total lead level in the meat from the wound 
channel was observed. In the control sample of the wild boar no visible fragments were seen (image not presented). Similar results are shown in the X-Ray images of the roe deer (gutted and skinned) and the flattened roe deer wound channel sample (Fig. 2a and b, respectively), although the number of visible fragments in the latter is lower compared with the wild boar. The differences in the fragmentation pattern between the investigated wild boar and roe deer could be explained by a variety of factors like bullet type, caliber, tissue resistance due to shot placement, distance to the prey etc. Because the purpose of this work was to investigate if any PbNPs could be detected in the samples, no further examination of these factors was performed.

Fig. 1 X-Ray images of a) the wild boar shoulder where the bullet hit behind the shoulder blade and fragmented and $b$ ) the flattened homogenized subsample taken around the wound channel. Note that the visible $\mathrm{Pb}$ particles (white arrows) are not evenly distributed in the sample.
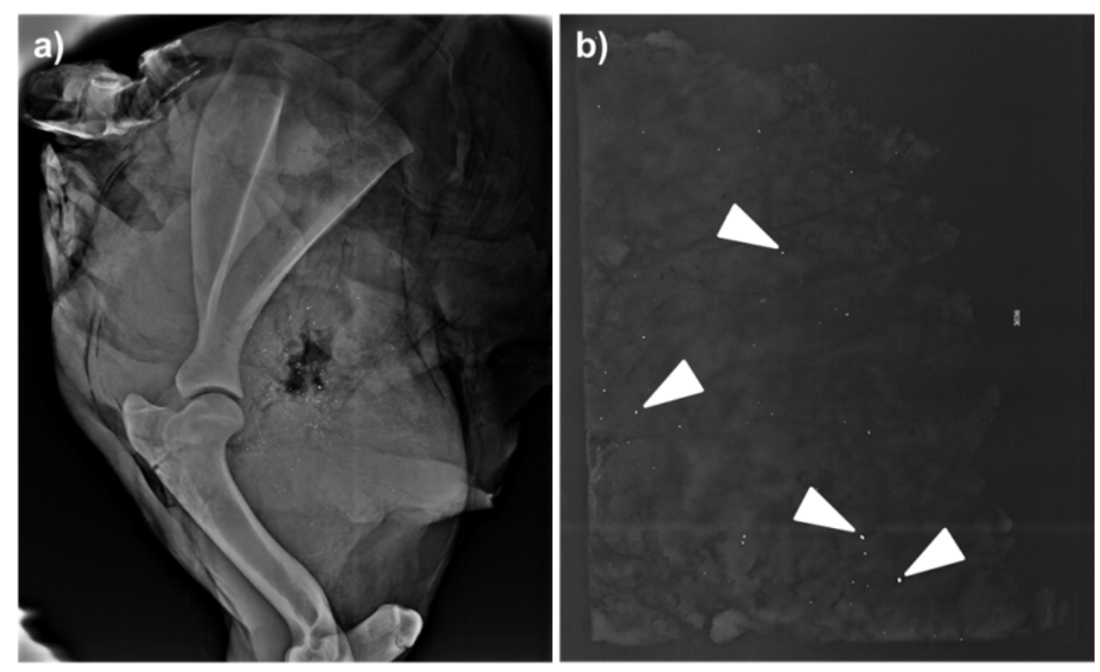

Fig. 2 a) X-Ray image of the roe deer (gutted and skinned) shot with a bonded bullet just behind the shoulder. Fragments are seen around the wound channel. b) X-Ray image of the flattened homogenized subsample taken around the wound channel. Note that the visible $\mathrm{Pb}$ particles (white arrows) are not evenly distributed in the sample.
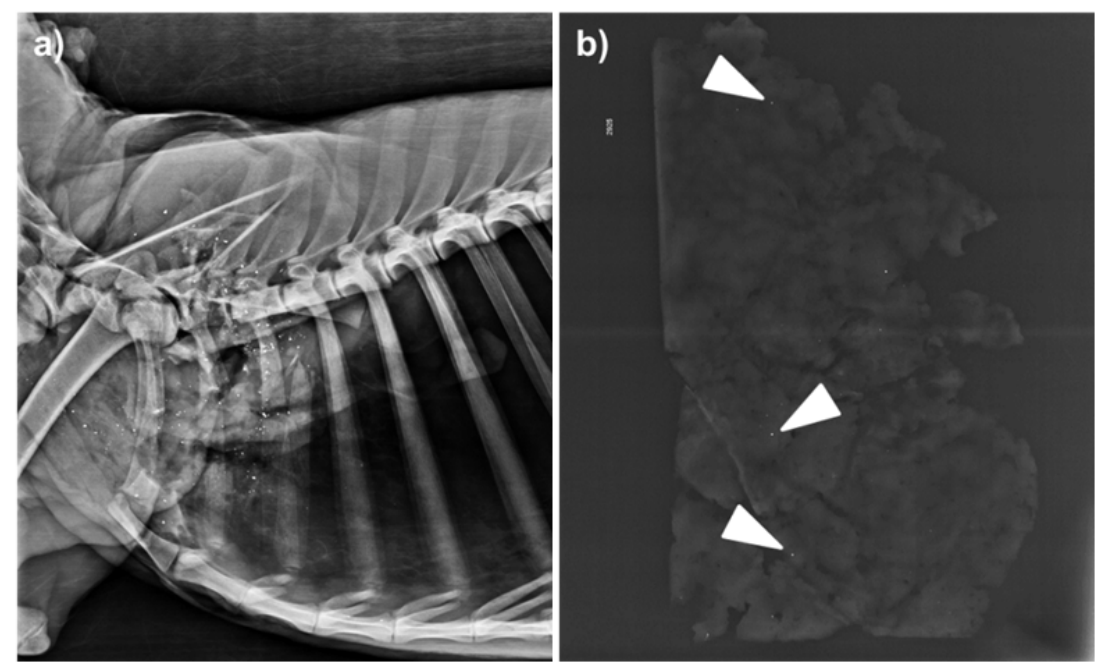


\section{2 spICP-MS analysis of the samples}

\subsubsection{Wild boar samples}

Fig. 3 presents the spICP-MS raw data for the $1 \mathrm{~h}$ enzymatically digested wild boar wound channel sample. The intense signals superimposed on the base line in the time resolved ICP-MS signal represent PbNPs (Fig. $3 \mathrm{a}$ ) and $\mathrm{b}$ ). Their heights correspond to the $\mathrm{Pb}$ mass. The elevated baseline at around 2,500 counts (corresponding to approximately $1.6 \mathrm{ng} / \mathrm{L}$ ) was caused by dissolved $\mathrm{Pb}$ (Fig. 3b), which limited the minimum detectable particle diameter to approximately $56 \mathrm{~nm}$ (Table 2). The base-line signal level of the control sample was significantly lower at approximately 10 counts (Fig. 3c). This low level was similar in magnitude to the time resolved signal of the sample preparation blank (data not presented). In the control sample and the sample preparation blank around 100 to $150 \mathrm{PbNPs}$ with median diameters of 12 to $18 \mathrm{~nm}$ (corresponding to peak signals of around 20 to 50 counts) were detected during the analysis time of $180 \mathrm{~s}$. The finding of small PbNPs in the sample preparation blanks suggests carry-over of PbNPs from previous analyses or formation of PbNPs in the sample introduction system from remaining $\mathrm{Pb}$ ions. Interestingly, no PbNPs were detected in ultrapure water which was analyzed after each sample for $180 \mathrm{~s}$. This indicates that the release of PbNPs from the surfaces of the sample introductions system was caused by the anionic surfactant SDS in the enzyme solution or the enzyme itself. A prolonged rinsing procedure with a surfactantcontaining acid mixture after analysis of each sample is expected to significantly reduce carry-over. Any remaining presence of PbNPs in the control samples could then be appropriately evaluated.

Fig. 3 Analysis of the enzymatically digested wild boar samples ( $1 \mathrm{~h}$ enzymatic digestion) by spICP-MS; Overview of the time-resolved ICP-MS signal for ${ }^{208} \mathrm{~Pb}$ in single particle-mode (a) and zoom of the time resolved signals for the wound channel (b) and the control sample (c), respectively. The dashed line in (b) indicates the threshold for particle detection based on the 5-sigma criterion.

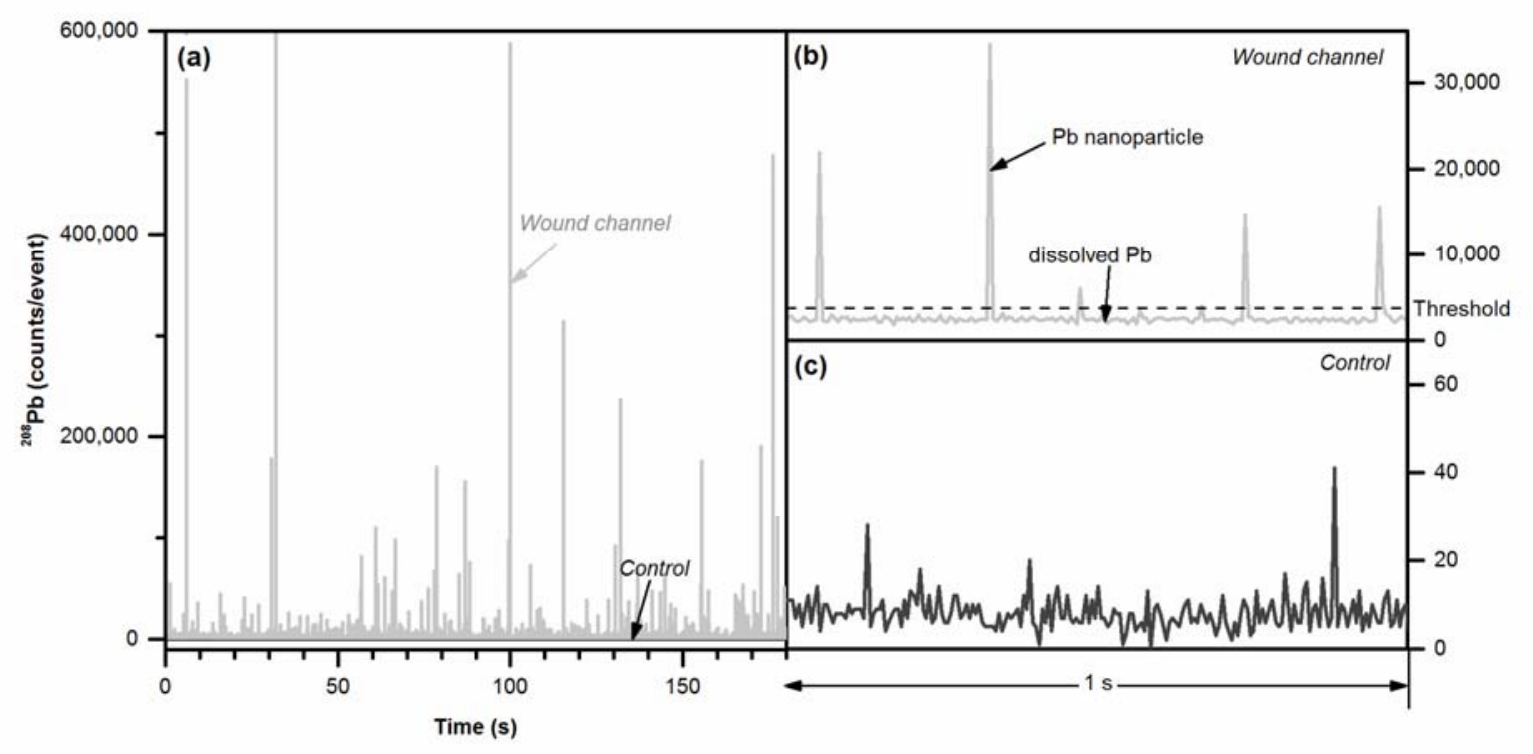


Table 2: spICP-MS results for wild boar samples $(\mathrm{N}=2)$. The control sample was taken 10-15 cm away from the wound channel, i.e. from meat intended to eat. The LOD for mass concentration of dissolved $\mathrm{Pb}$ in the samples was $50 \mathrm{ng} / \mathrm{g}$.



The carry-over of 12 to $18 \mathrm{~nm}$ PbNPs had no influence on the analysis of the wound channel samples as the size LOD for these samples was limited to $56 \mathrm{~nm}$ due to the level of dissolved $\mathrm{Pb}$. No PbNPs $\geq 56 \mathrm{~nm}$ were found in the two sample preparation blanks (per $180 \mathrm{~s}$ ) and two of the four control samples. In two control samples 1 or 3 particles (per $180 \mathrm{~s}$ ), respectively, were detected. The LOD for (dissolved) Pb mass concentration in the samples, recorded in spICP-MS mode, was calculated to be $50 \mathrm{ng} / \mathrm{g}$ (6-times standard deviation of sample preparation blank; mean of two blanks). In the wild boar control sample (taken 10-15 $\mathrm{cm}$ away from the wound channel) the mass concentration of dissolved $\mathrm{Pb}$ was below the LOD.

The resulting histograms (Fig. 4) showed that the major fraction of detected PbNPs in the wild boar wound channel was below $100 \mathrm{~nm}$ in diameter and that the largest detected PbNP was around $570 \mathrm{~nm}$. The diameters were calculated by assuming spherical PbNPs of homogenous density. Future work needs to study the shape and chemical composition of the detected PbNPs by additional methods like field flow fractionation or transmission electron microscopy in combination with energy-dispersive X-Ray spectroscopy to verify these assumptions. In general, an agglomerate or aggregate of several primary particles is identified as one large particle by spICP-MS. At high particle masses incomplete particle vaporization and non-linear detector responses might result in an underestimation of the PbNP diameter [27]. These effects strongly depend on the particle density, the fraction of the analysed element in the particle, and the boiling point [27]. Calibration curves based on AuNPs of defined sizes showed negative deviations from the linear behaviour for $250 \mathrm{~nm}$ AuNPs [27]. As Pb has a lower density and boiling point than $\mathrm{Au}$, it can be expected that deviations occur for particle diameters above $250 \mathrm{~nm}$. The trueness of the determined size values from spICP-MS can only be evaluated by comparison with size information from other methods due to the lack of suitable ( $\mathrm{PbNP}$ ) reference materials and standard particles [28].

PbNPs ( $\geq 56 \mathrm{~nm}$ ) constituted $10 \%$ by mass of the total Pb concentration determined by spICP-MS for $1 \mathrm{~h}$ enzymatic digestion. It has to be kept in mind that a large fraction of PbNPs smaller than $56 \mathrm{~nm}$ is most likely present in the sample but could not be detected because of the high dissolved $\mathrm{Pb}$ level. In the absence 
of any dissolved $\mathrm{Pb}$, a size LOD of around $10 \mathrm{~nm}$ could be obtained (data not presented). A reduction of the size LOD for samples with a high dissolved $\mathrm{Pb}$ level could be achieved by further dilution of the samples. The level of dissolved $\mathrm{Pb}$ would be decreased while the height of the signal caused by a single particle would remain the same. However, a corresponding extension of the analysis time would be required to allow the detection of the same number of PbNPs. Another alternative would be the use of microsecond instead of millisecond dwell times [29], which was not possible with the available instrumentation at the time when the experiments were performed. A reduction of the size LOD was beyond the scope of the presented work since the main focus was on investigation of the presence of PbNPs in meat from game shot with lead bullets.

Fig. 4 Number-based particle size distributions of PbNPs in the wild boar sample (wound channel) after $1 \mathrm{~h}$ and $16 \mathrm{~h}$ of enzymatic digestion. The dashed lines indicate the size limit of detection (LOD).

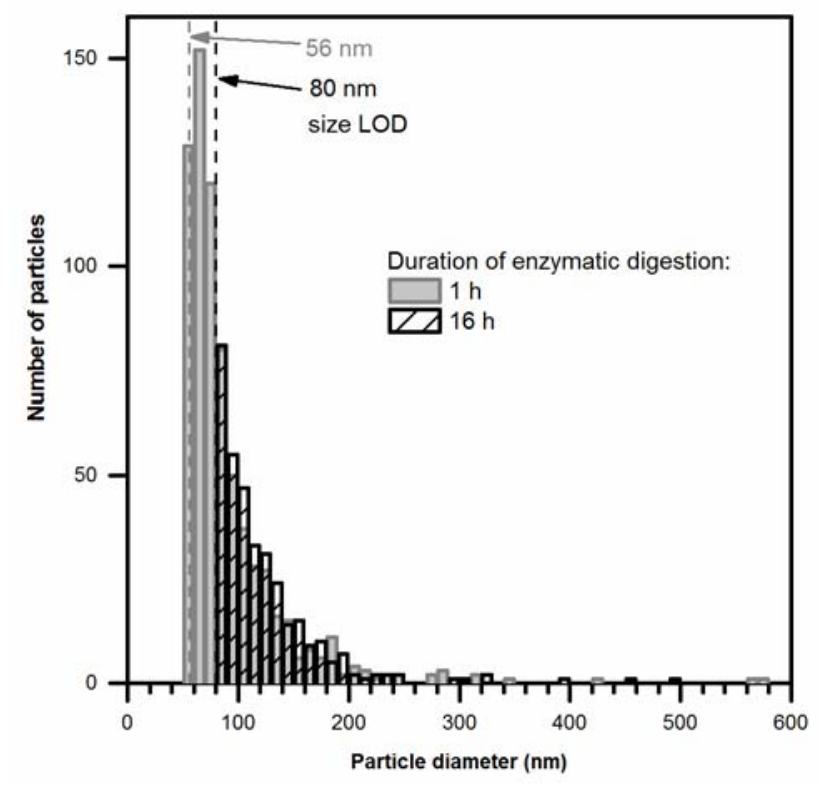

An increase of the enzymatic digestion time from $1 \mathrm{~h}$ to $16 \mathrm{~h}$ led to a decrease of the particle mass concentration and an increase of the mass concentration of dissolved $\mathrm{Pb}$ (Table 2). This finding indicated partial dissolution of the PbNPs during enzymatic digestion. The size limit of detection increased from $56 \mathrm{~nm}$ to $80 \mathrm{~nm}$ after $16 \mathrm{~h}$ enzymatic digestion (Fig. 4).

The determined total $\mathrm{Pb}$ concentration by spICP-MS (3 to $8 \mu \mathrm{g} / \mathrm{g}$ ) was significantly lower than the total $\mathrm{Pb}$ concentration determined by conventional ICP-MS $(300 \mu \mathrm{g} / \mathrm{g})$. This indicates that a large fraction of $\mathrm{Pb}$ in the samples was not assessable by the spICP-MS method. This fraction is most likely larger bullet fragments that are "lost" during sampling, or sample preparation, e.g. by sedimentation.

To evaluate the stability of the enzymatic digests, samples ( $1 \mathrm{~h}$ digestion; $\mathrm{N}=2)$ were re-analyzed after six days storage at $4^{\circ} \mathrm{C}$. The particle mass concentrations $(327 \pm 20 \mathrm{ng} / \mathrm{g})$ and the mass concentrations of 
dissolved $\mathrm{Pb}(3,929 \pm 374 \mathrm{ng} / \mathrm{g})$ were not significantly different from the samples directly analyzed after enzymatic digestion (one-way ANOVA, $p=0.103$ ).

\subsubsection{Roe deer samples}

In the wound channel of the roe deer, the concentration level of dissolved $\mathrm{Pb}$ was approximately 2-times lower than that in the wild boar $(1,200$ counts $/ \sim 0.8 \mathrm{ng} / \mathrm{mL}$ instead of 2,500 counts $/ \sim 1.6 \mathrm{ng} / \mathrm{mL})$. Therefore the minimum detectable diameter of the PbNPs was lower than for the wild boar (46 nm). In the control sample for the roe deer (hind leg steak), the number of detected PbNPs and the mass concentration of dissolved $\mathrm{Pb}$ were below the limit of detection. The wound channel sample showed a substantial amount of particles in the range 40 to $400 \mathrm{~nm}$ (Fig. 5). In contrast to the wild boar sample, no statistically significant increase (one-way ANOVA, $p=0.757$ ) in the dissolved $\mathrm{Pb}$ content was observed between 1 and $16 \mathrm{~h}$ enzymatic digestion times (Table 3 ).

Fig. 5 Comparison of the number-based particle size distributions of PbNPs in the roe deer and the wild boar sample (wound channel) after $1 \mathrm{~h}$ of enzymatic digestion. The dashed lines indicate the size limit of detection (LOD).

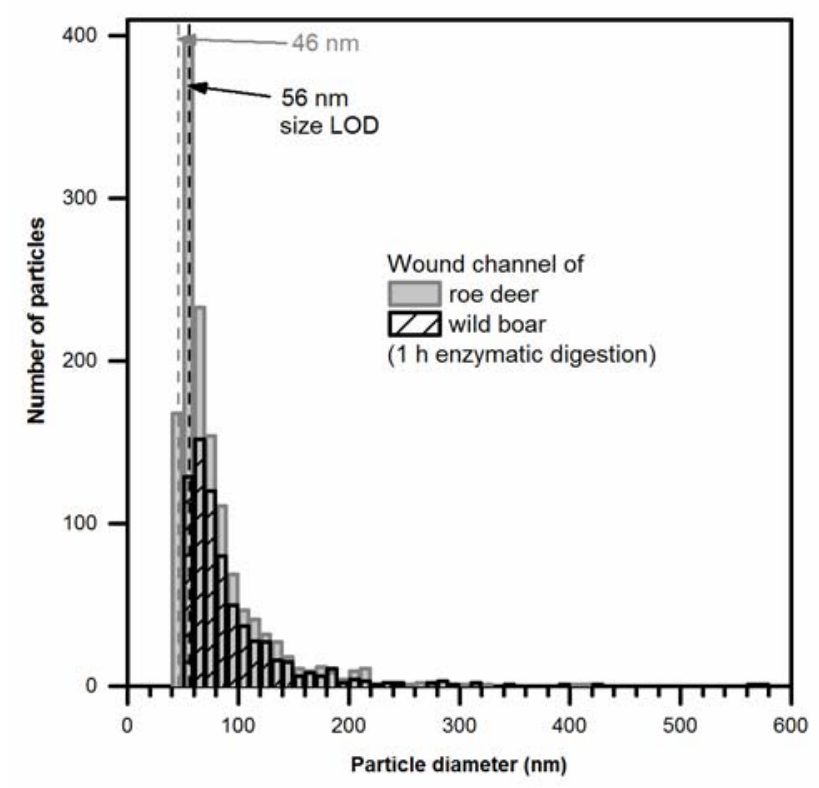

To evaluate the stability of the enzymatic digests, samples ( $1 \mathrm{~h}$ digestion; $\mathrm{N}=2$ ) were re-analyzed after three days storage at $4^{\circ} \mathrm{C}$. After storage, the particle mass concentrations $(30 \pm 2 \mathrm{ng} / \mathrm{g})$ and the mass concentrations of dissolved $\mathrm{Pb}(2,100 \pm 2 \mathrm{ng} / \mathrm{g})(\mathrm{N}=2)$ were significantly different from the samples analyzed immediately after sample preparation. The significant reduction of the particle mass concentration and the increase in the concentration of ions and non-detectable particles indicate dissolution of the PbNPs during storage. This was not observed for the wild boar samples.

The differences in mass concentration of PbNPs and in particle size between the wound channel samples of wild boar and roe deer could be explained by a variety of factors like bullet type characteristics (thickness of 
jacket, amount of antimony added to the lead, chemical bonding of the core to the jacket), caliber, weight of the bullet, resistance encountered for the penetrating bullet, , or distance from hunter to the prey. These effects may also explain the observed differences of the stability of the enzymatic digests over several days. In general, the finding of a large quantity of dissolved $\mathrm{Pb}$ in the particle-containing meat samples is not surprising. In air, the surface of metallic $\mathrm{Pb}$ is quickly covered by lead oxide $(\mathrm{PbO})$, which serves as a protective layer against further oxidation [30]. In aqueous media [30] and in physiological fluids [31, 32], $\mathrm{PbO}$ dissolves, and continuous dissolution of the metal occurs if oxygen is present. The dissolution rate may vary widely with $\mathrm{pH}$-value of the surrounding medium and with the composition of the solution, e.g. the presence ions and organic acids or proteins, which may act as complexation ligands [32]. Smaller $\mathrm{Pb}$ particles are more likely to dissolve completely due to their larger surface to volume ratio compared to bigger particles [9]. Dissolution of the $\mathrm{Pb}$ bullet fragments in the meat can occur during transport and storage of the animal carcass as well as in the prepared samples. The analytical procedure must therefore be designed in accordance with the purpose of the analysis, i.e. depending if the interest concerns the original PbNPs in the meat, or whether it aims at the PbNPs that might remain at the time of consumption. In this work the purpose was to show the bare presence of PbNPs in lead shot tissue.

Table 3: spICP-MS results for roe deer $(\mathrm{N}=2)$. The LOD for mass concentration of dissolved $\mathrm{Pb}$ in the samples was $40 \mathrm{ng} / \mathrm{g}$.

\begin{tabular}{|c|c|c|c|c|c|c|c|}
\hline & $\begin{array}{c}\text { Duration } \\
\text { of } \\
\text { enzymatic } \\
\text { digestion } \\
(\mathrm{h})\end{array}$ & $\begin{array}{c}\text { number of } \\
\text { detected } \\
\text { particles } \\
(\geq 43 \mathrm{~nm})\end{array}$ & $\begin{array}{c}\text { size } \\
\text { LOD } \\
(\mathrm{nm})\end{array}$ & $\begin{array}{c}\text { median } \\
\text { particle } \\
\text { diameter } \\
(\mathrm{nm})\end{array}$ & $\begin{array}{c}\text { number } \\
\text { concentration of } \\
\text { PbNPs } \\
\left(10^{6 *} \text { particles/g) }\right.\end{array}$ & $\begin{array}{c}\text { mass } \\
\text { concentration } \\
\text { of PbNPs } \\
(\mathrm{ng} / \mathrm{g})\end{array}$ & $\begin{array}{c}\text { mass } \\
\text { concentration } \\
\text { of dissolved } \\
\mathrm{Pb}(\mathrm{ng} / \mathrm{g})\end{array}$ \\
\hline \multirow{2}{*}{ control } & 1 & 0 & - & - & - & $<\mathrm{LOD}$ & $<\mathrm{LOD}$ \\
\cline { 2 - 8 } & 16 & $2 \pm 3$ & - & - & - & $<$ LOD & $<$ LOD \\
\hline $\begin{array}{c}\text { wound } \\
\text { channel }\end{array}$ & 1 & $1,362 \pm 19$ & $46 \pm 2$ & $63 \pm 3$ & $51.8 \pm 0.4$ & $289 \pm 55$ & $1,176 \pm 142$ \\
\cline { 2 - 8 } & 16 & $953 \pm 144$ & $43 \pm 4$ & $57 \pm 6$ & $35.8 \pm 5.3$ & $114 \pm 16$ & $1,093 \pm 297$ \\
\hline
\end{tabular}

\section{Summary and conclusions}

$\mathrm{PbNPs}$ could be detected in game meat and their size distribution determined. To the best of our knowledge, this is the first time that the occurrence of nanometre-sized lead particles in bullet-shot game is reported. The game meat intended to eat contained no PbNPs. However, the level of dissolved $\mathrm{Pb}$ in the samples limited the minimum detectable particle diameter to approximately 46 (roe deer) and $56 \mathrm{~nm}$ (wild boar). An improvement of the method towards lower size LODs will be required to assure that no smaller PbNPs are present in game meat. This is of particular importance since it is well known that some hunters also consume the meat close the wound channel [33].

Our finding makes enzymatic digestion followed by spICP-MS analysis a promising methodology for detection and characterization of size and number of PbNPs in game meat. Further work is necessary to 
validate the method in relation to particle size and mass concentration. An extended study focusing on the influence of bullet types, animal species, sampling and sample preparation parameters will give further insight in the mechanisms involved in PbNP dissolution. For evaluation of the potential toxicity of the $\mathrm{PbNPs}$, careful characterization of their physico-chemical properties including chemical composition, impurities, particle size and size distribution, shape, surface chemistry, degree of agglomeration/aggregation, and solubility is required. A combination of several analytical techniques will be necessary to determine all these properties. Additionally, cell line and animal studies (oral exposure) would be required to evaluate the transportation routes of PbNPs in biological systems. Notable in this context is that, since metallic $\mathrm{Pb}$ dissolves in biological systems over time, there is a probability for larger metallic $\mathrm{Pb}$ fragments to partly dissolve on their way through the gastrointestinal tract and reach the size of nanoparticle that could penetrate the membranes and enter the blood system. However, independently of the origin of the PbNPs, the distribution and later dissolution of the PbNPs in the body are of toxicological interest, especially if the absorbed PbNPs can pass through cell barriers.

\section{Conflict of Interest}

The authors declare that they have no conflict of interest.

\section{Compliance with Ethical Standards}

Samples were collected from animals already harvested through regular hunting for obtaining game meat and regulating populations. Thus, no ethical permits were needed (Swedish Animal Welfare legislation, 2016).

\section{Acknowledgements}

We thank Marianne Hansen for her assistance during the study.

\section{References}

1. EFSA (2010) Scientific Opinion on Lead in Food (EFSA Panel on Contaminants in the Food Chain). EFSA J 8:1570. doi: 10.2903/j.efsa.2010.1570.

2. EFSA (2012) Lead dietary exposure in the European population. EFSA J 10:2831. doi: 10.2903/j.efsa.2012.2831.

3. World Health Organization (2011) Evaluation of certain food additive and contaminants (Section 5.2 Lead). World Health Organ Tech Rep Ser 960:162-177.

4. Dobrowolska A, Melosik M (2008) Bullet-derived lead in tissues of the wild boar (Sus scrofa) and red deer (Cervus elaphus). Eur J Wildl Res 54:231-235. doi: 10.1007/s10344-007-0134-y

5. Hunt WG, Watson RT, Oaks JL, Parish CN, Burnham KK, Tucker RL, Belthoff JR, Hart G (2009) Lead bullet fragments in venison from rifle-killed deer: Potential for human dietary exposure. PLoS One 4:1-6. doi: 10.1371/journal.pone.0005330

6. Iqbal S, Blumenthal W, Kennedy C, Yip FY, Pickard S, Flanders WD, Loringer K, Kruger K, Caldwell KL, Jean Brown M (2009) Hunting with lead: association between blood lead levels and wild game consumption. Environ Res 109:952-959. doi: 10.1016/j.envres.2009.08.007 
7. Bjermo H, Sand S, Nälsén C, Lundh T, Enghardt Barbieri H, Pearson M, Lindroos AK, Jönsson BAG, Barregård L, Darnerud PO (2013) Lead, mercury, and cadmium in blood and their relation to diet among swedish adults. Food Chem Toxicol 57:161-169. doi: 10.1016/j.fct.2013.03.024

8. Meltzer HM, Dahl H, Brantsæter AL, Birgisdottir BE, Knutsen HK, Bernhoft A, Oftedal B, Lande US, Alexander J, Haugen M, Ydersbond TA (2013) Consumption of lead-shot cervid meat and blood lead concentrations in a group of adult Norwegians. Environ Res 127:29-39. doi:

10.1016/j.envres.2013.08.007

9. Kollander B, Sundström B, Widemo F, Ågren E (2014) Lead in game meat, part 1 - Ammunition residues and chemical analysis. Natl. Food Agency's Rep. Ser. no. 18/2014

10. Arnemo JM, Andersen O, Stokke S, Thomas VG, Krone O, Pain DJ, Mateo R (2016) Health and Environmental Risks from Lead-based Ammunition: Science Versus Socio-Politics. Ecohealth. doi: 10.1007/s10393-016-1177-x

11. Knott J, Gilbert J, Hoccom DG, Green RE (2010) Implications for wildlife and humans of dietary exposure to lead from fragments of lead rifle bullets in deer shot in the UK. Sci Total Environ 409:95-99. doi: 10.1016/j.scitotenv.2010.08.053

12. Finney MA, McAllister SS, Maynard TB, Grob IJ (2016) A Study of Wildfire Ignition by Rifle Bullets. Fire Technol 52:931-954. doi: 10.1007/s10694-015-0518-6

13. Krug HF, Wick P (2011) Nanotoxicology: an interdisciplinary challenge. Angew Chem Int Ed Engl 50:1260-78. doi: 10.1002/anie.201001037

14. Fröhlich E, Roblegg E (2012) Models for oral uptake of nanoparticles in consumer products. Toxicology 291:10-7. doi: 10.1016/j.tox.2011.11.004

15. Binderup M-L, Bredsdorff L, Beltoft VM, Mortensen A, Loeschner K, Larsen EH, Eriksen FD (2013) Systemic Absorption of Nanomaterials by Oral Exposure (Report to The Danish Environmental Protection Agency, Environmental Project No. 1505).

16. Laborda F, Bolea E, Jimenez-Lamana J (2014) Single Particle Inductively Coupled Plasma Mass Spectrometry: A Powerful Tool for Nanoanalysis. Anal Chem 86:2270-2278. doi: dx.doi.org/10.1021/ac402980q

17. Degueldre C, Favarger P-Y (2003) Colloid analysis by single particle inductively coupled plasmamass spectroscopy: a feasibility study. Colloids Surfaces A Physicochem Eng Asp 217:137-142. doi: 10.1016/S0927-7757(02)00568-X

18. Laborda F, Jiménez-Lamana J, Bolea E, Castillo JR (2011) Selective identification, characterization and determination of dissolved silver(i) and silver nanoparticles based on single particle detection by inductively coupled plasma mass spectrometry. J Anal At Spectrom 26:1362. doi:

$10.1039 / \mathrm{c} 0 \mathrm{ja} 00098 \mathrm{a}$

19. Mitrano DM, Lesher EK, Bednar A, Monserud J, Higgins CP, Ranville JF (2012) Detecting nanoparticulate silver using single-particle inductively coupled plasma-mass spectrometry. Environ Toxicol Chem 31:115-21. doi: 10.1002/etc.719

20. Loeschner K, Navratilova J, Købler C, Mølhave K, Wagner S, von der Kammer F, Larsen EH (2013) Detection and characterization of silver nanoparticles in chicken meat by asymmetric flow field flow fractionation with detection by conventional or single particle ICP-MS. Anal Bioanal Chem 405:8185-95. doi: 10.1007/s00216-013-7228-z

21. Loeschner K, Brabrand MSJ, Sloth JJ, Larsen EH (2014) Use of alkaline or enzymatic sample pretreatment prior to characterization of gold nanoparticles in animal tissue by single-particle ICPMS Characterisation of Nanomaterials in Biological Samples. Anal Bioanal Chem 406:3845-3851. doi: 10.1007/s00216-013-7431-y

22. Loeschner K, Harrington CF, Kearney J-L, Langton DJ, Larsen EH (2015) Feasibility of asymmetric flow field-flow fractionation coupled to ICP-MS for the characterization of wear metal particles and metalloproteins in biofluids from hip replacement patients. Anal Bioanal Chem 407:4541-4554. doi: $10.1007 / \mathrm{s} 00216-015-8631-4$

23. Sand S, Darnerud PO (2014) Lead in game meat, part 3 - Risk assessment. Natl. Food Agency's Rep. Ser. no. $18 / 2014$

24. Bjerselius R, Halldin Ankarberg E, Kautto A (2014) Lead in game meat, part 4 - Risk management. Natl. Food Agency's Rep. Ser. no. 18/2014

25. Pace HE, Rogers NJ, Jarolimek C, Coleman V a, Higgins CP, Ranville JF (2011) Determining 
transport efficiency for the purpose of counting and sizing nanoparticles via single particle inductively coupled plasma mass spectrometry. Anal Chem 83:9361-9. doi: 10.1021/ac201952t

26. Tuoriniemi J, Cornelis G, Hassellöv M (2012) Size discrimination and detection capabilities of single-particle ICPMS for environmental analysis of silver nanoparticles. Anal Chem 84:3965-72. doi: $10.1021 /$ ac203005r

27. Lee W-W, Chan W-T (2015) Calibration of single-particle inductively coupled plasma-mass spectrometry (SP-ICP-MS). J Anal At Spectrom 30:1245-1254. doi: 10.1039/C4JA00408F

28. Loeschner K, Navratilova J, Grombe R, Linsinger TPJ, Købler C, Mølhave K, Larsen EH (2015) Inhouse validation of a method for determination of silver nanoparticles in chicken meat based on asymmetric flow field-flow fractionation and inductively coupled plasma mass spectrometric detection. Food Chem. doi: 10.1016/j.foodchem.2015.02.033

29. Montaño M, Badiei H (2014) Improvements in the detection and characterization of engineered nanoparticles using spICP-MS with microsecond dwell times. Environ Sci Nano 1:338-346. doi: 10.1039/C4EN00058G

30. Hägg G (1969) General and Inorganic Chemistry. Almquist and Wiksell, Stockholm

31. Fairhall L (1924) Lead studies. IX. The solubility of various lead compounds in blood serum. J Biol Chem 60:481-484.

32. Grant LD (2009) Lead and compounds. In: Lippmann M (ed) Environ. Toxicants Hum. Expo. Their Heal. Eff., 3rd ed. John Wiley \& Sons, Inc., Hoboken, NJ, USA, pp 757-809

33. Forsell K, Gyllenhammar I, Sommar J, Lundberg-Hallén N, Lundh T, Kotova N, Bergdahl I, Järvholm B, Darnerud P (2014) Lead in game meat, part 2 - Blood lead levels among families consuming game meat. Natl. Food Agency's Rep. Ser. no. 18/2014 